\title{
Dysgerminoma, Pyometra of the Stump and Mammary Carcinoma in a Female Dog with Ovarian Remnant Syndrome-Case Study
}

\author{
Ioana SFARTZ*, Petru ROŞCA, Iulian IBĂNESCU, Ioana CRIVEI, Dan DRUGOCIU \\ Faculty of Veterinary Medicine,Department of Clinics, University of Agricultural Sciences and Veterinary \\ Medicine of Iasi, Aleea M. Sadoveanu no. 3, 700490, Iasi, Romania \\ *Corresponding author: ioana_sfartz@yahoo.com
}

Bulletin UASVM Veterinary Medicine 72(2) / 2015,

Print ISSN 1843-5270; Electronic ISSN 1843-5378

DOI:10.15835/buasvmcn-vm: 11401

\begin{abstract}
Ovarian remnant syndrome (ORS) represents the presence of functional ovarian tissue after routine castration of the bitch, caused either by surgeon error or the presence of anomalous ovarian tissue. The piece of ovary that remains after the surgery, may continue to develop and become functional, secreting hormones as estrogen and progesterone which cause signs of pro-estrus or estrus, even pseudocyesis. All those signs cause consternation among owners, who thought that the reproductive activity in their dog will be completely abolished. One mixedbreed, 6 years old bitch, $27.3 \mathrm{~kg}$, spayed 8 months before, was presented with purulent vaginal discharge and mammary lumps, after the animal has been treated by her veterinarian with Proligestone to suppress the persisting estrus signs. Our investigations included vaginal cytology, vaginoscopy, the examination of the mammary chain, ultrasound, radiography, serum chemistry, blood count and histopathological examinations. The ultrasound revealed a filled uterine stump and the presence of a mass caudal the right kidney, which was suspected as an ovarian neoplasm. The examination of the mammary chain revealed masses in right M 3, M4, M5 glands and in the left M2 gland. The bitch underwent surgery, and the results of the histopathological examination were: dysgerminoma, pyometra, and the mammary masses were classified as carcinomas. In this paper we wanted to underline the fact that the Ovarian Remnant Syndrome may imply serious clinical consequences which can even lead to the death of the animal. We recommend as a method of treatment for this condition the surgical removal of the remnant tissue.
\end{abstract}

Keywords: bitch, ovarian remnant syndrome, pyometra, uterine stump

\section{INTRODUCTION}

The ovary of the bitch can be often the seat of pathogenically entities development, such as ovarian cysts or even neoplasia (Jones, 1983; Drugociu, 2009). Ovarian tumours can be of germinal cells, epithelial cells or sex stromal in origin (Sforna et al., 2003). The most important are the granulosa cell tumours, which can reach very large sizes, sometimes they can even secret progesterone, triggering cystic endometrial hyperplasia and pyometra or persistent oestrus (Sforna, 2003; Drugociu, 2009). Germinal cells tumours, dysgerminomas and teratomas, are less common in the bitch (Greenlee, 1985).
In order to prevent these diseases, as well as other concerning the reproductive system, the owners are often advised to spay their female dogs (Runceanu et al., 2007). Surgical neutering is one of the most common surgical interventions in the veterinary practice. However, even the most experimented practitioners can face the impossibility of fully removing the ovarian tissue, caused either by poor visibility of the surgical field, or because of improper application of clamps and ligatures, or sometimes, even because of the presence of some adhesions or lesions that make impossible to locate the ovaries (Chung, 2009). 
Ovarian remnant syndrome represents the persistence of functional ovarian tissue after routine spaying of the female dogs (Feldman, 2004; Runceanu, 2007; Drugociu, 2009). The ovarian cortex portion remaining after the surgery continues to grow, becoming functional, secreting hormones, progesterone and oestrogens (Feldman, 2004), just as the intact ovary, exerting effects on genital tract, mammary gland and the central nervous system, depending on the phases of the sexual cycle in which the animal is (Miller, 1995; Feldman, 2004).

According to Sorenmo (2013), there is a general agreement that the greatest benefit on mammary tumor prevention is seen if the dog is not allowed to go through any heat cycles, suggesting that the pivotal and irreversible effects of ovarian hormones on the mammary glands in terms of cancer risk occur early in life, likely during puberty when the mammary gland develops and mature, thus, the best way to prevent mammary cancer is the early spaying of the female dog. Also, exposure to exogenous or pharmacologic doses of hormones (both progestins and estrogens), however, has been found to increase the risk for developing mammary tumors in dogs. Thus, dogs treated with progestins are more likely to develop tumors and are younger when they do. According to the Norwegian Canine Cancer Registry, dogs treated with progestins to prevent estrus had a 2.3 times higher risk for mammary tumors when compared to dogs not receiving such treatment (Stroving, 1997).

Our study presents the ovarian remnant syndrome in a 6 years old mixed breed bitch, diagnosed with ovarian dysgerminoma, pyometra of the stump and mammary carcinoma.

\section{MATERIALS AND METHODS}

The patient, a 6 years old, mixed breed female dog, weighing $27,3 \mathrm{~kg}$, was presented in our clinic 8 months after she was castrated in a private clinic. The female had only one litter, 3 years before being spayed and received progestogens several times (4-5 times) before the surgical spaying. The owners have reported the presence of some mammary lumps that have significantly increased in volume in a relatively short time (several months). The doctor who operated the animal later admitted (3 months after the surgery, when the owners were surprised to find that their pet is still receptive to males) the possibility of failing to completely remove one of the ovaries because of the presence of some adhesions. On medical advice, the owners have opted for a contraception with Proligestone injections. When the animal started to present mammary enlargements, the currant veterinarian interpreted this as canine lactatio sine graviditate, without performing additional exams.

When the owners brought the dog to our clinic, there was already a tennis ball-sized mass in the right M3 gland.

\section{RESULTS AND DISSCUSION}

On physical examination, it was found that the animal was spirited, with no signs of discomfort. The respiratory, cardiac frequencies as well as the rectal temperature were within normal limits. The patient was clinically examined by inspection and palpation, ascertaining the evident increase in the abdomen. Abdominal palpation revealed the presence of a hard, large, movable mass in the mid abdomen, but the patient did not show any sign of pain during this procedure. Palpation of mammary chain revealed the presence of some hard, with irregular contours, immovable masses in the right M3 (2 cm diameter), M4 (1 $\mathrm{cm}$ diameter) and M5 glands ( $8 \mathrm{~cm}$ diameter) and the left $\mathrm{M} 2$ gland $(3,5 \mathrm{~cm}$ diameter). The size and consistency of the reginal lymph nodes were within physiological norms. Following this examination, it was suspected the presence of mammary tumors, therefore radiologic examination was performed to verify the presence for metastases, particularly of the lungs, common in mammary neoplasia (Kealy et al., 2011). The result was negative (Fig.1 (a,b)).

On gynecological examination, it was found the presence of malodorous purulent vulvar discharge. With the vaginal speculum and a light source it was observed the light edema of the vaginal mucosa and the presence of the purulent discharge. The vaginal smear cytology performed by Diff-Quick staining revealed a high number of large superficial cells, characteristic in estrogenic secretion (Noakes et al., 2001; Feldman, 2004), also numerous bacteria and neutrophils.

The ultrasound examination, performed with a $7.5 \mathrm{MHz}$ sectoral transducer, showed the presence of a large heterogeneous mass, caudal to the right kidney (Fig. 2), which was suspected as an ovarian neoplasm (Kealy et al., 2011). Also, there was a distended, convoluted, thin-walled 
tubular uterus stump in the caudal abdomen, dorsal to the urinary bladder, containing fluid (Fig. 3,4). All other structures seemed unmodified in the abdominal cavity (Barr, 2011; Kealy et al., 2011).

Results were completed by a complete blood count that revealed a hemoglobinemia $(7,89 \mathrm{mmol} / \mathrm{l})$, a hematocrit of $39 \mathrm{l} / \mathrm{l}$, leukocytosis (20G/l), neutrophilia $(81,2 \%)$, lymphopenia $(4,32 \%)$, monocytosis $(8,98 \%)$, an increased value of basophil granulocytes $(2,22 \%)$, other values were within species normal limits. Blood chemistry results were also within physiological limits.

Linking the anamnestic data with the clinical and laboratory findings, the presumptive diagnosis of ovarian remnant syndrome, ovarian tumor, uterine stump pyometra and mammary neoplasia was established.

It has been decided to intervene surgically, urgently, to remove the abdominal mass, the uterine stump, and to perform total mastectomy of the right mammary chain (being more than 3 glands affected) (Sorenmo, 2013) and a partial

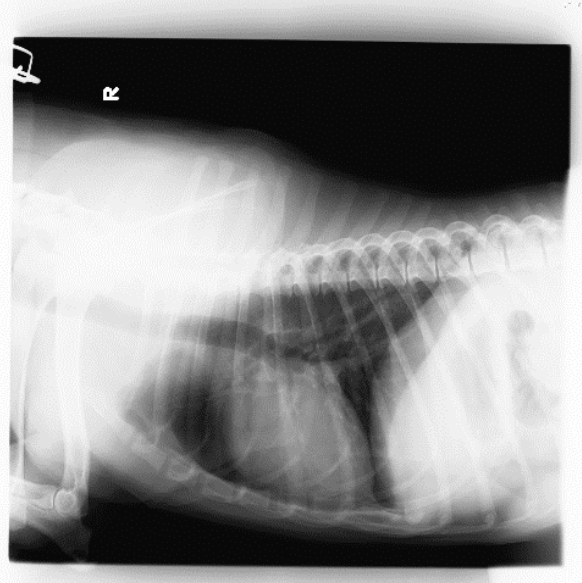

a)

Fig. 1. (a, b) Thoracic radiography, lateral decubitus position (right (a) and left (b)); lack of visible lung metastases in a mixed-breed, 6 years old female dog

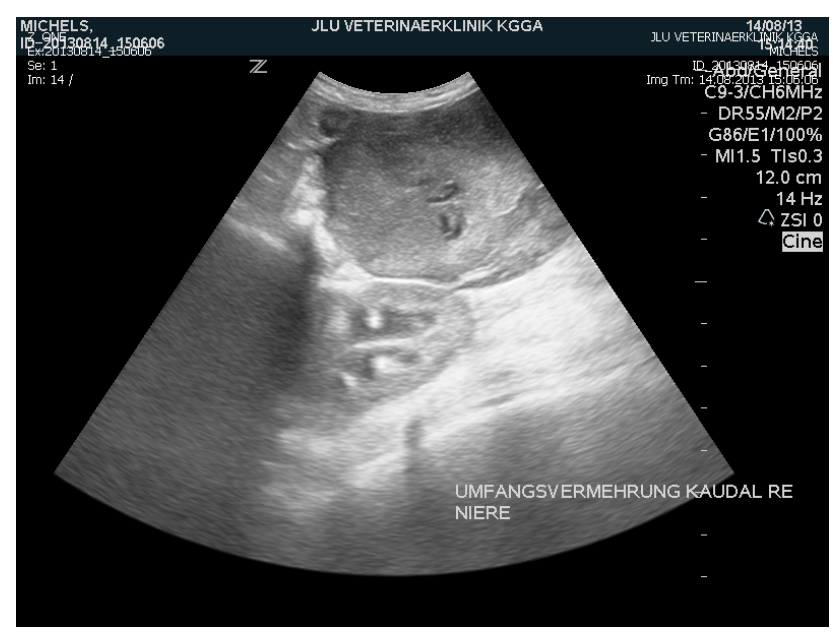

Fig. 2. Neoplasia caudal to right kidney-ultrasound aspect in a 6 years old mixed breed female dog

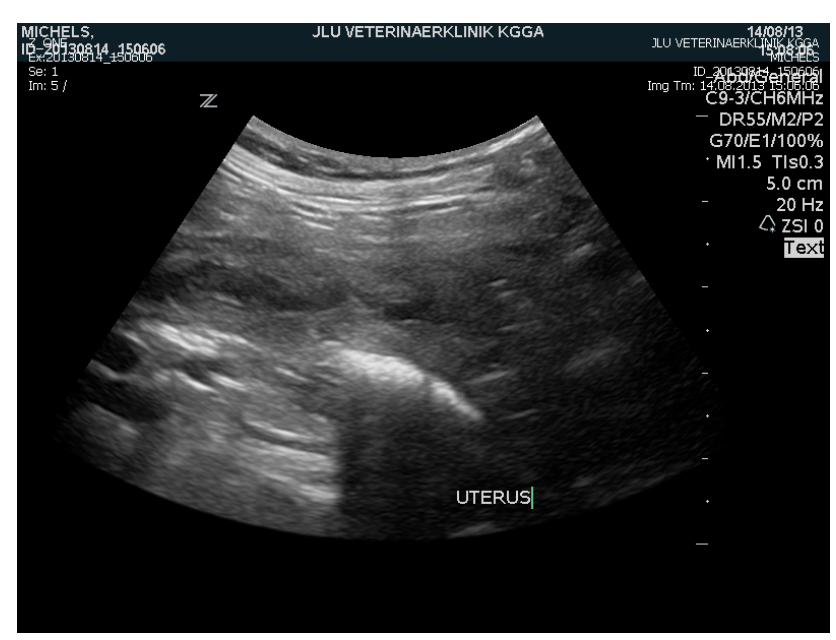

Fig. 3. Distended uterine stump-ultrasound aspect in a 6 years old, mixed breed female dog 


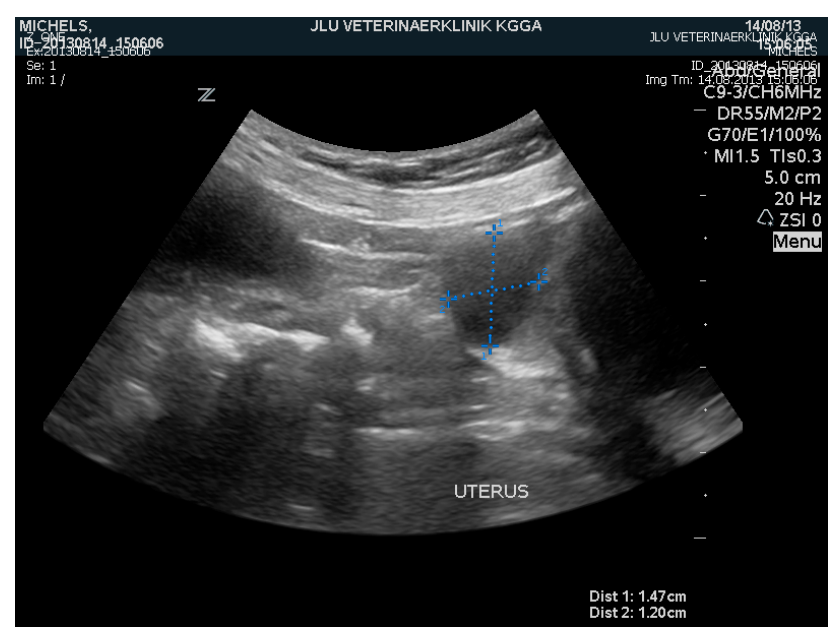

Fig. 4. Uterine stump diameter-ultrasound aspect in a 6 years old mixed breed female dog

left mammary chain mastectomy, being one single gland affected.

The ovarian tumor mass was completely removed, submitted in $10 \%$ formalin and sent to the laboratory for histopathological examination, along with the uterine stump, that was highly enlarged and filled with a purulent fluid (Fig.5). After checking for the metastasis presence in the abdominal cavity, the abdominal wall was sutured in continues thread, and then the mastectomies were performed. The neoplastic mammary masses have been completely removed up to healthy tissue, being also stored in $10 \%$ formalin and sent to the laboratory along with the other samples for histopathologic differentiation.

The histopathologic examination results have showed: in the right M3 gland- focal hyperplasia and ductal epithelium sclerosis; in the right M4 gland- development of strong infiltrating carcinoma process; in the right M5 gland (the biggest among the mammary masses) - partially tubule-papillary complex, partially carcinoma extensive necrosis and purulent infiltration in the central portion-mixed tumor process, granulation tissue. In the left M2 gland-cystic papillary carcinoma. The abdominal ovarian mass was differentiated as dysgerminoma. In the uterine stump, numerous neutrophilic granulocytes could be observed in the lumen, also an endometrial squamous metaplasia and cell residues of placental trophoblasts insertion. Thus the final diagnosis

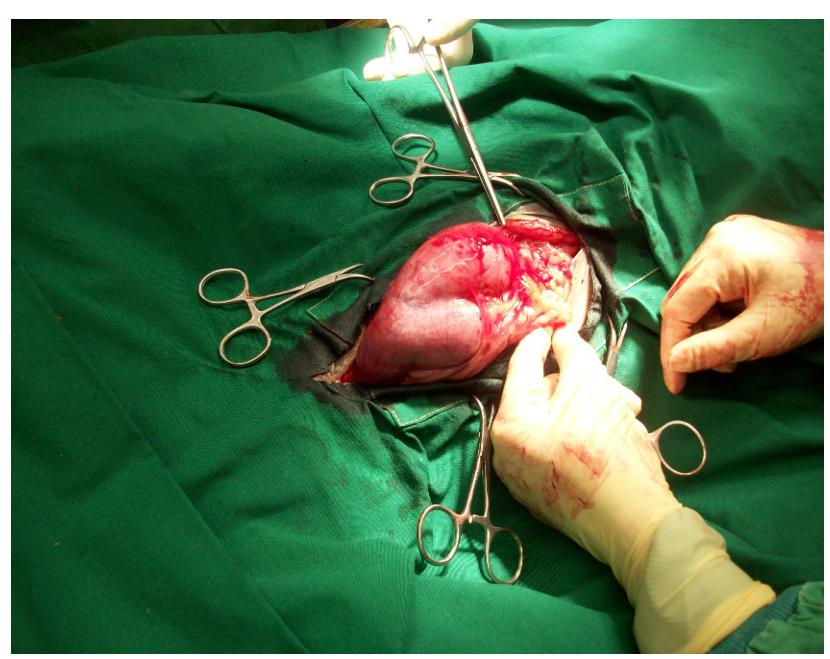

Fig. 5. Distended uterine stump, filled with a purulent fluid- aspect during surgery in a 6 years old mixed breed female dog

was dysgerminoma, uterine stump pyometra and mammary carcinoma.

The patient made an uneventful recovery after the surgery, the medication she received postsurgery was: Metacam, Synulox, Meloxicam and Lymphomyosot $\mathrm{N}$. At the 12 days check-up consult the general state of the animal was very good, she only presented a small surgical wound infection that was properly treated (with local disinfection and antibiotic ointment (Sorenmo, 2013).

One month postoperatively, the bitch was submitted at our clinic with bulky new operative wound infection, purulent discharge and pain on palpation of the mammary chain. By palpation, a rice grain-sized mass was found in the left M3 gland, another one of $10 \times 10 \times 4 \mathrm{~cm}$, hard, immobile in the left M4 gland and a $1 \mathrm{~cm}$ in diameter one in the left M5 gland. The complete blood count revealed a leukocytosis $(15,7 \mathrm{G} / \mathrm{l})$. The dog was sent back home with an analgesic and antibiotic treatment, and should be presented in a few days to a new consultation. Three days later, the patient was brought in a critical condition, presenting metastases in the entire mammary chain, the impossibility of taking the stern-abdominal decubitus position because of the serious pain, thus, along with the owners, the decision of euthanasia was taken.

\section{CONCLUSION}

This case demonstrates that the remaining portion of the ovary after incomplete castration 
continues to grow, it becomes functional and secrete hormones that exert a strong influence on genital tract and mammary gland. Also, the remaining portion of the ovary can become the seat of neoplastic formations. We recommend in case of ovarian remnant syndrome, the exploratory laparoscopy, the identification and surgical removal of remaining ovarian tissue before any other treatment methods. We also advice to take into consideration the effects of progestins upon the mammary gland. For the avoidance of uterine disorders, hormone-dependent, such as cystic endometrial hyperplasia- pyometra, we recommend total hysterectomy for conventional castration. This case is one of the worst scenarios for the evolution of ovarian remnant syndrome.

\section{REFERENCES}

1. Barr F, Gaschen L (2011). BSAVA Manual of Canine and Feline Ultrasonography. British Small Animal Veterinary Association, 172-176.

2. Chung Fat B, Terzibachian JJ, Bertrand V, Leung F (2009). Ovarian remnant syndrome: Diagnostic difficulties and management. Gynecologie Obstetrique \& Fertilite 37:488494.

3. Drugociu D( 2009). Bolile obstetrical ginecologice la animale, Ed a ll-a. Ed „Ion Ionescu de la Brad”, Iaşi.

4. Feldman EC, Nelson RW (2004). Canine and Feline Endocrinology and Reproduction, Third Edition. Section
Seven-Canine Female Reproduction, Chapter 19: Ovarian cycle and vaginal cytology, Saunders.

5. Greenlee PG, Patnaik AK (1985). Canine Ovarian Tumors of Germ Cell Origin. Vet Pathol 22:117-122.

6. Jones TC, Hunt RD (1983).The genital system: diseases of the ovary. In : Jones TC, Hunt RD (eds). Veterinary Pathology, Lea \& Febiger ,Philadelphia.

7. Miller DM (1995). Ovarian remnant syndrome in dogs and cats:46 cases (1988-1992). Vet Diagn Invest 7:572.

8. Kealy KJ, McAllister H, Graham J (2011). Diagnostic Radiology and Ultrasonography of the Dog and Cat, Fifth Edition. Sauders Elsevier, 181-190.

9. Noakes D, Parkinson T, England G (2001). Arthurs Veterinary Reproduction and Obstetrics, 8th Edition, Elsevier Limited , 5-10.

10. Runceanu L, Cotea C, Drugociu D, Roşca P (2007). Reproducție, Obstetrică şi Ginecologie Veterinară, Ediţia a ll-a. Ed "Ion Ionescu de la Brad", Iaşi.

11. Sforna M, Brachelente C, Lepri E, Mechelli L (2003). Canine Ovarian Tumors, A Retrospective Study of 49 Cases. Veterinary Research Communications 27(1):359-361 12.Sorenmo UK, Worley RD, Goldschmidt HM (2013). Tumors of the Mammary Gland. Withrow and Mcewen's Small Animal Clinical Oncology,Fifth Edition. Chapter 27, Part IV-Specific Malignancies in the Small Animal Patient, 538-556.

12. Stovring M, Moe L, Glattre E (1997). A population-based case-control study of canine mammary tumors and clinical use of medroxyprogesterone acetate. APMIS 105:590-596. 